\title{
Monitoring and Analysis of Construction Site Accidents by Using Accidents Analysis Management System in Turkey
}

\author{
Fatih Yilmaz ${ }^{1}$ \\ ${ }^{1}$ Department of Industrial Engineering, Faculty of Mechanical, Yildiz Technical University, Turkey \\ Correspondence: Fatih Yilmaz, Department of Industrial Engineering, Faculty of Mechanical, Yildiz Technical \\ University, Turkey. E-mail: fatihyilmaz59@gmail.com
}

Received: December 3, 2014

Accepted: December 8, 2014 Online Published: March 30, 2015

doi:10.5539/jsd.v8n2p57

URL: http://dx.doi.org/10.5539/jsd.v8n2p57

\begin{abstract}
Due to the inadequacy in measures at many construction sites in Turkey, approximately 400 workers died and hundreds of workers become permanently disabled in occupational accidents. Occupational accidents cause serious financial loss for both the company and the country economies. This study is conducted to analyze causes and results of occupational accidents at a construction site in Istanbul-Turkey. Research data consists of the accident statistics of a construction site in Istanbul, which is obtained by using "Retrospective Cohort" method. In this study, causes and results of occupational accidents, which occurred in the construction site, are investigated.

The main reasons for accident occurrence are "being hit by dashing and flitting objects", "being hit by objects", "falling objects" and "being stung by something". As a result of occupational accidents, injuries occurred in the form of incision, exposure to metal burrs, contusion, transient loss of vision, trauma and perforation. Eye, finger, foot and hand injuries are the most common accidents. The majority of occupational accidents occur on Mondays, in summer months and between the hours 16.00-18.00. The most important reason of occupational accidents is "unsafe behaviours" with a ratio of $67 \%$, which is defined as not to obey the rules although the necessary occupational safety measures are provided. 312 work-day losses occurred in the construction site during the monitoring period. All major and minor accidents in construction sites should be recorded, their causes should be investigated and all necessary measures should be provided. Construction enterprises should perform within the frame of a health and safety management system.
\end{abstract}

Keywords: safety, construction, accident analysis, preventive methods

\section{Introduction}

In every year, 60.000 fatal accidents occur worldwide in construction sector and one worker dies because of an occupational accident in every 10 minutes. Construction sector involves high risks due to its production processes and labor intensive characteristic and the sector is faced with financial loss in large scale because of occupational accidents. Occupational accidents also have a significant importance for sustainability of enterprises due to their costs and environmental impacts. Besides, especially great industrial occupational accidents pose important risks for both public health and environment (Takala, 1999; International Labour Office, 2004; Rubio, Martinez, Rubio \& Ordoñez, 2008).

Construction industry uses and produces a wide variety of manufactured components in addition to basic construction materials. There is a major manpower requirement to maintain production in a construction site under hard working conditions with hazardous materials and machines. Construction industry production process contains variety of occupational accident risks such as, falling from height, being hit by equipment, construction machinery and crane accidents, exposure to electric shock, explosion, and fire. Furthermore, exposure to burrs, toxic fumes and dusts occurred during welding works cause injuries or accidents that result in loss of working days (International Labour Office, 1992; Sorock, Smith \& Goldoft, 1993; Everett \& Frank, 1996; Tang, Lee \& Wong, 1997; Ikpe, Felix \& David, 2012). 
Table 1. Occupational accidents, occupational diseases, deaths and permanent disabilities in Turkish construction sector (Turkish statistical institute)

\begin{tabular}{lcccccccc}
\hline \multicolumn{1}{c}{ Years } & $\mathbf{2 0 0 5}$ & $\mathbf{2 0 0 6}$ & $\mathbf{2 0 0 7}$ & $\mathbf{2 0 0 8}$ & $\mathbf{2 0 0 9}$ & $\mathbf{2 0 1 0}$ & $\mathbf{2 0 1 1}$ & $\mathbf{2 0 1 2}$ \\
\hline Occupational Accident & 6480 & 7143 & 7615 & 5574 & 6877 & 6437 & 7749 & 9209 \\
Occupational Disease & 3 & 5 & 16 & 6 & 9 & 31 & 16 & 30 \\
Permanent Disability & 324 & 428 & 364 & 377 & 288 & 319 & 406 & 568 \\
Death & 290 & 397 & 359 & 297 & 156 & 475 & 570 & 256 \\
Ratio in Total Death Number & $26 \%$ & $25 \%$ & $34 \%$ & $34 \%$ & $13 \%$ & $33 \%$ & $33 \%$ & $34 \%$ \\
\hline
\end{tabular}

Construction sector, which has a great contribution to economic development with its employment capacity and added-value to the economy, is one of the most important sectors in developing countries. On the other hand, occupational accidents frequently occur, due to the lack of preventive measures.

According to Social Security Institution statistics, 6,000-9,000 occupational accidents occur in construction sector in Turkey and approximately 400 workers die and another 400 workers become permanently disabled in these accidents, annually (see Table 1). $34 \%$ of the deaths related with occupational accidents occur in construction sector. It is also observed that occupational accidents and deaths tend to increase in recent years. Studies show that occupational accidents and diseases in construction sector cause serious financial losses for both enterprises and country (Arioglu, 2002; Baradan, 2006; Ofluoglu \& Dogru, 2011; Turkey Statistical Institute, 2013).

According to studies investigated in developed countries, main reasons of occupational accidents are; inadequacy of trainings and personal protection equipment that provided to employees, not implementing "working at height" methods, not carrying out periodic maintenance and systematic environment measurements, working with subcontractors and inadequacy of inspections. In addition, managerial faults stand out during analyzing the reasons of accidents. It was observed that some major and minor occupational accidents were not recorded, reasons of these accidents were not analyzed, risk assessments were not prepared well enough and precautions were not managed and thus, it is asserted that accidents occur due to these lacknesses (Leopold \& Leonard, 1987; Saari \& Näsänen, 1989; Sorock et. al., 1993; Everett, 1995; Salminen, 1995; Jeong, 1998; Rivara \& Thompson, 2000; Mohamed, 2002; Tang, Ying, Chan \& Chan, 2004; Rubio et. al., 2008; Barlas, 2012).

However, there are no sufficient studies on this issue in Turkey. Findings related with causes and results of accidents in Turkish construction sector are obtained from the limited studies. The main causes of accidents are as follows; being unprepared for the rapidly increasing demand; the subcontractor system that cannot work regularly; the lack of qualified intermediate staff; the lack of education of employees in the construction sites and the lack of audit. The risk of possible accidents in construction sites depend on five different reasons; falling from height, falling objects and being hit by objects, machinery and crane accidents, electric shock, and explosion. In Turkey, $90 \%$ of workers are subcontracted from third party companies in construction sector. Subcontractor system, limit the organization and to take measures for workers' health and safety. Working in open areas under cold and hot weather, rain, wind and similar bad weather conditions can cause dangerous working conditions and hazardous behaviors. Nevertheless, there are no studies that the monitoring and analysis of work-related accidents at the workplace level. (Arioglu \& Arioglu, 1997; Ercan, 2010; Mungen, 2011).

Accidents are not recorded in many construction sites in Turkey. Thus, the losses caused by work-related accidents are not known, preventive measures can not be taken at a adequate level. Analyzing occupational accidents occurred in construction sites is important for identifying risks correctly, preparing occupational safety plans in workplaces, conducting occupational safety works systematically and avoiding from accidents that might occur in the future.

The research aims to analyzing occupational accidents, investigate their reasons and establishing a management system with the aim of helping to plan preventive actions by revealing factors that might create risks at the construction sites.

Based on past studies and results of this research conducted in a construction site in Turkey, the aims of this study are as below;

a) To classify occupational accidents in construction site,

b) To determine causes of accidents, 
c) To specify dangerous behaviours of workers,

d) To present the results derived from these dangerous behaviours,

e) To determine the results of occupational accidents in terms of workers and enterprises in construction sector in Turkey

f) To develop a monitoring and management system to follow and analyze occupational accidents in construction sites

g) To present the contribution of preventive studies to the sustainability of enterprises by reducing the losses occurred as a result of occupational accidents.

\section{Material and Method}

Research data is obtained with "Retrospective Cohort" method in a construction site in Istanbul-Turkey. 200 occupational accidents, which occurred in the site between February 2012-November 2013, are investigated. Data is collected from the occupational physicians and safety experts' accident reports for registered occupational accidents. The process of obtaining and analyzing data with cohort method was monitored by occupational safety consultant of the construction site.

Retrospective cohort studies are based on records collected. Thus, the records must be accurate and reliable. At the planning stage of studies, it is determined how to create cohort and how long it is monitored by researchers. In the next step, the exposure conditions of patients in the cohort and the results are analyzed. It is determined how to define criteria for exposure at the planning stage. At the end of monitoring time, cause-effect relationships between accident and exposed risk factors are investigated. Retrospective cohort method is widely used in the investigation of workplace accidents (Liddell, McDonald, Thomas \& Cunliffe, 1977; Bergh, Ericson, Hillensjö, Nygren \& Wennerholm, 1999; Wild, Pierpoint, McKeigue \& Jacobs, 2000; Tang et. al., 2004; Krstev, Stewart, Rusiecki \& Blair, 2007; Brant et. al., 2009; Ascioglu, 2012; Tudor et. al., 2014).

Before the beginning of the study, the enterprise is informed about the research objectives, scope and methodology. Firstly, the software is designed to make data collection easier. Visual Basic based software (Accidents Analysis and Management System) is developed for analyzing detailed occupational accidents easier and faster. This software offers obtaining large amount of data about occupational accidents from the chosen site. In addition, the some of the most important advantages of the software are ability of obtaining charts about accidents, making analysis based on the types of accidents, determining divisions where accidents happen etc. The lack of safety requirement related with the job can easily be realized by analyzing these charts. Then, occupational health and safety personnel (site safety experts, occupational physician and occupational health nurse) were informed about the program. Data collection process was followed by weekly periods; occupational accidents and exposure information were recorded in detail during 22-month period.

In the light of the collected data by means of the computational software, 200 major and minor accidents in construction site were determined and classified by types, the causes and demographic characteristics of exposed workers by analyzing all of the factors that cause occupational accidents. The victim's age, gender, education level, department, cause of accident, accident date, type of the injury and accident, workday losses and other related information were collected. The findings of 'accident investigation reports' must be considered in order to determine the causes of the occupational accidents. The total of workdays was 290 ; monthly average number of workers was 302; the total working hours was 700,640 for the construction project in 2013.

2 serious occupational accidents, a "falling from height" and a "falling object", occurred during the project and both of them resulted with disability more than 30 days.

\section{Results}

$29 \%, 21 \%$ and $13 \%$ of workers who exposed to occupational accident in construction site are unqualified workers, molders and plumber, respectively. Because the monitoring period is rough construction stage, occupational accidents occurred for these occupational groups more. Besides, the great number of unskilled workers in the construction site causes more occupational accidents for these occupational groups.

Young workers are highly employed due to the heavy duty conditions in construction sites, age groups of 18-24 and 25-39 are exposed to $44 \%$ and $52 \%$ of occupational accidents, respectively. In consideration of the age group of 18-39 is exposed to $96 \%$ occupational accidents, it can be understood that young workers sustain injuries more (see Table 2). 
Table 2. Distribution of accident rates with respect to duties and age groups (\%)

\begin{tabular}{|c|c|c|c|c|c|}
\hline \multirow[b]{2}{*}{ Duties of Workers } & \multicolumn{5}{|c|}{ Age Groups of Workers } \\
\hline & $18-24$ & $25-39$ & $40-54$ & $40-54$ & Total \\
\hline Watchman & & & & 1 & 1 \\
\hline Painter & 1 & 4 & & & 5 \\
\hline Smith & 5 & & & & 5 \\
\hline Mason & 3 & 1 & & & 4 \\
\hline Unskilled Worker & 12 & 17 & & & 29 \\
\hline Ganger & & 1 & & & 1 \\
\hline Electrician & 1 & 6 & & & 7 \\
\hline Foreman & & 1 & 1 & & 2 \\
\hline Administrative Personnel & & 1 & & & 1 \\
\hline Molder & 11 & 10 & & & 21 \\
\hline Welder & & 1 & 1 & & 2 \\
\hline Fitter & 3 & 1 & & & 4 \\
\hline Operator & & & 1 & & 1 \\
\hline Plasterer & 1 & 3 & & & 4 \\
\hline Plumber & 7 & 6 & & & 13 \\
\hline Total & 44 & 52 & 3 & 1 & 100 \\
\hline
\end{tabular}

"Being hit by dashing and flitting object" is the most common reason for occupational accidents in the construction site with a ratio of $23 \%$. All of these types of accidents are exposed by young workers, who belong to 18-39 age group. "Being hit by objects" (18\%) is the second most common type of accident. After these, "falling objects" (15\%), "being stung by something" (11\%) are the most common reasons, respectively. Besides, workers who are in the age group of 25-39 and 18-24 are mostly exposed to "being hit by object" (12\%) and "being hit by dashing and flitting object" (12\%), respectively. "Falling objects" accidents are also affected noteworthily to the workers in the age group of 25-39. Due to power and strength requirements, manual handling or handling with the aid of some equipment, are performed by young workers more, it can be deduced that young workers expose to "falling objects" accidents more. Worker, who are above 40, generally don't work on active duties. Skilled workers, foremen, chiefs, technicians and administrative personnel expose to occupational accidents less.

Table 3. Distribution of accident rates with respect to types of accidents and age groups (\%)

\begin{tabular}{lccccc}
\hline \multicolumn{1}{c}{ Type of Accident } & \multicolumn{5}{c}{ Age Group of the Workers } \\
\hline \multicolumn{1}{c}{$18-24$} & $25-39$ & $40-54$ & $40-54$ & Total \\
\hline Falling from the same level & 3 & 3 & & & 6 \\
Hit to an object & 2 & 6 & 1 & 1 & 10 \\
Being stung by an object & 6 & 4 & 1 & & 11 \\
Being hit by an object & 6 & 12 & & 18 \\
Dashing or flitting object & 12 & 11 & & 23 \\
Being squeezed between or under two people & 5 & 1 & & 6 \\
Fight & & 1 & & 1 \\
Exposure to welding beam & 1 & & & & 1 \\
Exposure to chemicals & 1 & & & \\
Falling object & 4 & 10 & 1 & & 1 \\
Drifting or rubbing & 1 & 1 & & & 2 \\
Falling from height & 1 & 2 & & & 3 \\
Being forced & 2 & 1 & & $\mathbf{1}$ \\
Total & $\mathbf{4 4}$ & $\mathbf{5 2}$ & $\mathbf{3}$ & $\mathbf{1}$ \\
\hline
\end{tabular}


It is observed that unskilled worker exposure to "being stung by an object" with the rate of $7 \%$; plumbers and unskilled workers exposure to "being hit by dashing or flitting objects" with the rate of $6 \%$. Also, molders expose to "falling objects" by $5 \%$ and electricians, molder and plumbers expose to "being hit by an object" by $4 \%$.

$63 \%$ of all occupational accidents are exposed by unskilled workers, molder or plumbers. These workers, who are uneducated and even illiterate, are faced with difficulties in adapting to the rules of occupational safety, they pay no attention to the rules, disuse the equipment and it result in fatal accidents. Some of these workers are employed for a brief and temporary period and thus, they have difficulties in adapting to physical and working conditions. Besides, because the workers are employed for a temporary period; they are forced to work rapidly since they are undeclared worker. It is obviously seen that these conditions invite the accidents.

According to the research; the most common result of injuries from occupational accidents is "incision" (29\%). Incision is followed by exposure to metal burr (14\%), contusion, transient loss of vision and trauma (11\%), perforation (10\%) and bruise (7\%). Eye, finger, foot, hand and leg are the most common injured body parts with ratios of $25 \%, 19 \%, 12 \%, 11 \%$ and $9 \%$, respectively. Eyes are effected most $(14 \%)$ by the metal burrs that are produced as a result of hot working such as metal cutting and welding processes; fingers (11\%), hands $(8 \%)$ and face $(5 \%)$ are effected most by frequent use of drilling and cutting tools; feet are effected most by falling objects with a result of perforation. Due to exposure to chemical vapor, hot weather and intense beam; transient loss of vision may occur $(11 \%)$. Several processes are performed with an intense usage of labor force. Thus, these processes include accident risks that may cause not only partial injuries for different organs but also major injuries to the whole body and can result in even death. Because the necessary measures are taken, personnel protective equipment (PPE) and educations are provided completely in the construction site in which this study was applied, most of the accidents are got off lightly. On the other hand, because these measures aren't taken in many construction sites in Turkey, a great number of deadly occupational accidents occur.

Most of the occupational accidents in the construction site occur on Monday (23\%). Tuesday (17\%), Wednesday and Saturday (15\%) are the other days on which accidents occur commonly. Number of occupational accidents is found to be decreased on Sundays since there is less work on Sundays frequently. Due to the lack of motivation after weekend holiday, it is meaningful that Mondays are the days on which accidents occur most. While occupational accidents occur more frequently in summer months, they occur less in winter months due to the cold weather and slow process. Besides, it is determined that $40 \%, 50 \%$ and $10 \%$ of the occupational accidents occur during first 3 , during $4^{\text {th }}-6^{\text {th }}$ and during $7^{\text {th }}-8^{\text {th }}$ working hours, respectively.

Table 4. Distribution of accident rates with respect to months and days (\%)

\begin{tabular}{|c|c|c|c|c|c|c|c|c|}
\hline \multirow[b]{2}{*}{ Accident Month } & \multicolumn{8}{|c|}{ Accident Day } \\
\hline & Sunday & Monday & Tuesday & Wednesday & Thursday & Friday & Saturday & Total (\%) \\
\hline January & & 1 & 1 & 1 & 1 & & & 4 \\
\hline February & & 2 & 1 & 2 & & & & 5 \\
\hline March & 2 & 1 & 3 & & 1 & 2 & 1 & 10 \\
\hline April & & 2 & 2 & 1 & & 1 & 2 & 8 \\
\hline May & 1 & 1 & 1 & 1 & 1 & 1 & & 6 \\
\hline June & & 1 & 2 & 2 & & 1 & 2 & 8 \\
\hline July & & & 4 & 1 & 1 & & 2 & 8 \\
\hline August & & 2 & 2 & 3 & 1 & 2 & 1 & 11 \\
\hline September & 2 & 6 & & 1 & 2 & & 2 & 13 \\
\hline October & & 3 & & 2 & 2 & 1 & 1 & 9 \\
\hline November & & 3 & 1 & 1 & 2 & 4 & 3 & 14 \\
\hline December & 1 & 1 & & & 1 & & 1 & 4 \\
\hline Total (\%) & 6 & 23 & 17 & 15 & 12 & 12 & 15 & 100 \\
\hline
\end{tabular}

Dangerous behaviors that may cause an accident and the places at which an accident occur are investigated within the scope of the research. According to the results, the main reason of the accidents is "unsafe 
behaviours" (67\%) which can be defined as not to obey the rules despite the safety measures are taken. The second most common cause of accident is not to use the personal protective equipments (12\%). Using the equipment and tools in a dangerous way is the third most common reason ( $8 \%$ ). "Working dangerously fast" and "unsuitable stowing and loading" are also important reasons of accidents. While the majority of the accidents ( $62 \%$ ) occur in the building which is constructed, $28 \%$ of the accidents occur at open fields in the construction site. The remarkable fact in the data is determining that a significant amount of accidents occur not only in the buildings that are constructed but also at outdoor environments as open construction fields. Especially the number of accidents, which occur as a result of falling objects that carried by heavy duty vehicles, must be less. These results show that the measures taken in the outdoor environment are inadequate and neglected.

130 of the 200 ( $65 \%$ ) occupational accidents occurred during the monitoring period are escaped lightly without workday loss. 28, 20 and 14 of 200 accidents, which correspond $14 \%, 10 \%$ and $7 \%$, respectively, caused 1,2 and 10 workday losses, respectively. "Dashing and flitting objects", "being hit by an object" and "falling objects" are the most common reasons of accidents that cause workday loss. Especially accidents related with falling objects, dashing objects and falling from height cause longtime treatment and recovery duration.

312 days of workday loss, which is related with occupational accidents, occurred during monitoring period. The total labor cost is calculated as $\$ 14,040$ by multiplying the average daily labor wage, which is $\$ 45$, with 312 lost days. Occupational accidents don't only mean workday loss, for certain. The direct and indirect costs such as damages in the machines, loss of stuff, treatment costs, loss of efficiency and the cost of the unworked period, must be considered. However, because the records of occupational accidents aren't kept well in Turkey, the costs of the accidents can't be calculated for certain and thus, the enterprises must bear great costs.

Table 5. Distribution of work-day losses with respect to types of accidents

\begin{tabular}{|c|c|c|c|c|c|c|c|c|}
\hline \multicolumn{9}{|c|}{ Number of Work-day Loss } \\
\hline \multicolumn{9}{|c|}{2} \\
\hline & Without day & 1 & $\mathrm{da}$ & 3 & 10 & 16 & 30 & Total Occupational \\
\hline Type of Accident & loss & day & ys & days & days & days & days & Accidents \\
\hline Falling from same level & 6 & 2 & 4 & & & & & 12 \\
\hline Hit to an object & 14 & 4 & 2 & & & & & 20 \\
\hline Being stung by an object & 12 & 4 & 6 & & & & & 22 \\
\hline Being hit by an object & 26 & 2 & & 2 & 6 & & & 36 \\
\hline Dashing or flitting objects & 38 & 6 & & & & & 2 & 46 \\
\hline \multicolumn{9}{|c|}{ Being squezed between or under } \\
\hline two people & 8 & & 2 & 2 & & & & 12 \\
\hline Fight & 2 & & & & & & & 2 \\
\hline Exposure to welding beam & & 2 & & & & & & 2 \\
\hline Exposure to chemicals & & 2 & & & & & & 2 \\
\hline Falling objects & 16 & & 6 & & 8 & & & 30 \\
\hline Drifting or rubbing & & 4 & & & & & & 4 \\
\hline Falling from height & 4 & & & & & 2 & & 6 \\
\hline Being forced & 4 & 2 & & & & & & 6 \\
\hline Frequency & 130 & 28 & 20 & 4 & 14 & 2 & 2 & 200 \\
\hline
\end{tabular}

\section{Discussion}

In this study, 200 accidents are defined to the software for examination. The result of this study shows the facts about the ages, occupation and education level of the victims, injured parts of the body, severity of injury, unsafe behavior that cause accidents and types of accidents.

There have been no fatal accidents in the site during the research period. Only 2 severe injuries occurred. Nevertheless, it is known that minor occupational accidents, which are not considered sufficiently and even not 
registered, cause great financial loss in workplaces. While 9 major accidents, which cause disability for more than 10 days, occur in the construction site during the monitoring period, the others are minor accidents that cause disability for less than 3 days.

According to the results of the study, $29 \%$ and $21 \%$ of workers, who are exposed to occupational accident, are unskilled workers and molders, respectively. $44 \%$ and $52 \%$ of the accidents affected workers in 18-24 and 25-39 age groups, respectively. Majority of the accidents caused by "dashing and flitting objects", "being hit by an object", "falling objects" and "being stung by an object". The injuries as a result of accidents are "incision", "exposure to metal burr", "transient loss of vision", "trauma" and "perforation", respectively. Eye, finger, foot and hand injuries are the most common areas that affected from the injury. Most of the accidents occur on Mondays, in summer months and during $4^{\text {th }}-6^{\text {th }}$ working hours.

According to the results of this research, 'unsafe behaviours', which is defined as not to obey the rules despite the necessary measures are taken, is the most important reason for accidents with a rate of $67 \%$. Not using the 'personal protective equipment' and 'using the tools and equipment in a dangerous way' are the other important causes of accidents. In spite of all warnings, measures and trainings, personal protective equipments aren't used effectively and regularly. Especially hand tools and lifting machines such as crane and forklift are used in dangerous way and for the wrong purposes.

312 workday losses occurred as a result of occupational accidents during the monitoring period. The total labor costs of these accidents are calculated as $\$ 14,040$. Although the costs of 2 severe accidents aren't counted in the calculation, the workday losses reach a significant level for the enterprise.

The physical, mechanical and personal protective measures are taken at a good level in the construction site. Risk analyses are prepared and updated regularly. There are occupational safety specialist, occupational physician and site control officers in the construction site. The equipments are maintained and controlled periodically, personal protective equipments are provided and workers are trained, regularly. Working hours are arranged in accordance with legal limitations. Therefore, except the 2 severe accidents, which resulted with disability for more than 30 days, no accidents occurred that may result with permanent disability or death during the duration of the project.

On the other hand, despite all of the measures and controls, dangerous behaviours of the workers can't be prevented. Workers avoid obeying the rules and are poor in terms of occupational safety culture. Workers have a low general and vocational education level. In general, they are young, brave and excited. Fatalistic beliefs prevail among the workers in accordance with the national traditions of Turkish people. Therefore, the managers and engineers remain incapable to prevent the dangerous behaviours despite all efforts and measures.

\section{Conclusion and Recommendations}

This research was conducted to determine the causes, results and dangerous behaviours of accidents in construction sites in Turkey. The study is also aims to develop an accident analyze and management system software. In this way, the study aims to present the contribution of preventive measures to the sustainability of enterprises by reducing the losses occurred as a result of accidents.

Hundreds of serious accidents occur in Turkey due to lack of attention, dangerous behaviours, disregarding the occupational safety rules, disapplying the rules of working at height, disusing of the lifting vehicles and hand tools, which have a high potential for accidents, lack of maintenance and control of the equipment, lack of experts, technical staffs, inspections and trainings. While 400 workers dies in every year in construction sector, approximately 400 workers become permanently disable also. Thus, keeping the statistics, investigating the causes and results of all accidents and taking measures according to these data are crucial requirements. Financial and moral losses of occupational accidents cause important socio-economic problems for sustainable developing enterprises, environment and society.

However, occupational accident statistics in Turkey are far from the truth due to sweeping the events under the carpet, informality, unregistered worker. Besides, public officers working in construction sites are not taken into account in the statistics since they are not considered as workers. Moreover, the enterprises aren't attentive to keep proper records and being a part of statistics analysis. Thus, the total financial losses can't be calculated in many enterprises.

According to a study conducted in a construction site in Turkey (Tan, 2002), a fatal accident causes $\$ 74.500$ financial loss totally for a construction enterprise. However, these costs can be prevented by spending up to half of it. In this research, although any accident that resulted with permanent disability or death haven't been occurred, the workday losses caused by minor and major accidents reached an important number. If these losses 
can be reduced to half, extra 312 workers, whose daily wage is $45 \$$, can be employed with a 14,000 \$ earning. Likewise, an important machine or engine can be bought.

Although the main reason of the accidents is determined as dangerous behaviours of the workers, it is also well known that managerial faults have an important effect on the accidents. In brief, ignorance, disregarding and lack of equipment, which are the main reasons of dangerous behaviours, must be investigated and thus, the necessary measures must be taken in order to minimize these reasons. At this point, systematic trainings of occupational safety play a key role.

Besides, the workers must report the improper practices, obey the occupational safety rules and demand from administration to take measures. All employees have to pay attention to use PPE. Educational, instructional and informative occupational safety seminars, which cover all topics and risks, should be conducted. Necessary interventions should be done to avoid mistakes after examining the occupational safety reports that are prepared by both company and whole sector. Trainings should be given regularly until the workers interiorize the usage of personal protective equipment as an obligation.

It is well understood that occupational safety related studies in construction sites should be carried out within the frame of a management system and detailed report of occupational accidents occurred in the sites should be kept. Risk assessment studies should be focused and revised in the light of examination of causes and results of accidents in detail. In order to minimize the occupational accidents and protect the workers in a long term, traditional production methods should be replaced with developed production technologies.

\section{References}

Arioglu, E. (2002). To reduce accidents should be increasing the overall efficiency of the sector. Journal of Soil Employers, 54, 1-4, (in Turkish).

Arioglu, E., \& Arioglu, N. (1997). Statistical evaluation and minimizing of occupational accidents in the Turkish construction sector. Concrete-Prefabrication Magazine, 2, 16-21, (in Turkish).

Ascioglu, S. (2012). Empirical study designs used in the hospital infections research. Journal of IKU, 26, 29-24.

Baradan, S. (2006). The place of safety in construction in Turkey and comparison of developed countries. $D E U$ Journal of Science and Engineering, 8(1), 87-100.

Barlas, B. (2012). Occupational fatalities in shipyards: an analysis in Turkey. Brodogradnja, 63, 35-41.

Bergh, T., Ericson, A., Hillensjö, T., Nygren, K. G., \& Wennerholm, U. B. (1999). Deliveries and children born after in-vitro fertilisation in Sweden 1982-95: A retrospective cohort study. The Lancet, 354(6), 1579-1580. http://dx.doi.org/10.1016/S0140-6736(99)04345-7

Brant, A., Upchurch, S., van Tongeren, M., Zekveld, C., Helm, J., Barnes, F., Newman, T.A.J., \& Cullinan, P. (2009). Detergent protease exposure and respiratory disease: case-referent analysis of a retrospective cohort. Occupational Environment Medicine, 66(11), 754-758. http://dx.doi.org/10.1136/oem.2008.043851

Ercan, A. (2010). Evaluation of the health and safety of workers in the construction sector in Turkey. Journal of Polytechnic, 13(1), 49-51, (in Turkish).

Everett, J. (1995). True costs of construction accidents: hidden incentive for construction automation and robotics. In E. Budny, A. McCrea, \& K. Szymanski (Eds.), Automation and Robotics in Construction XII.

Everett, J., \& Frank, P.B. (1996). Costs of accidents and injuries to the construction industry. Journal of $\begin{array}{llll}\text { Construction } \quad \text { Engineering } & \text { Management, } & \text { ASCE, } & 122(2),\end{array}$ http://dx.doi.org/10.1061/(ASCE)0733-9364(1996)122:2(158)

Ikpe, E., Felix, H., \& David, O. (2012). Cost-benefit analysis for accident prevention in construction projects. Journal of Construction Engineering and Management, American Society of Civil Engineers, August 2012, 991-998. http://dx.doi.org/10.1061/(ASCE)CO.1943-7862.0000496

International Labour Office (ILO). (1992). Safety and health in construction. In: ILO Code of Practice. Geneva: ILO Publication.

International Labour Office (ILO). (2004). Labour statistics. Geneva: ILO Publication.

Jeong, B. Y. (1998). Occupational deaths and injuries in the construction industry. Applied Ergonomics, 29(5), 355-360. http://dx.doi.org/10.1016/S0003-6870(97)00077-X 
Krstev, S., Stewart, P., Rusiecki, J., \& Blair, A. (2007). Mortality among shipyard Coast Guard workers: a retrospective cohort study. Occupational and Environmental Medicine, 64, 651-658. http://dx.doi.org/10.1136/oem.2006.029652

Leopold, E., \& Leonard, S. (1987). Costs of construction accidents to employers. Journal of Occupational Accidents, 8(4), 273-294. http://dx.doi.org/10.1016/0376-6349(87)90004-6

Liddell, F. D. K., McDonald, J. C., Thomas, D. C., \& Cunliffe, S. V. (1977). Methods of cohort analysis: appraisal by application to asbestos mining. Journal of the Royal Statistical Society, 140(4), 469-491. http://dx.doi.org/10.2307/2345280

Mohamed, S. (2002). Safety climate in construction site environments. Journal of Construction Engineering and Management, 128(5), 375-384. http://dx.doi.org/10.1061/(ASCE)0733-9364(2002)128:5(375)

Mungen, U. (2011). The main types of work-related accidents in the construction sector. Journal of TMH, Chamber of Civil Engineers, 469(5), 33-39, (in Turkish).

Ofluoglu, G., \& Dogru, T. (2011). The economic dimension of occupational accidents in the construction sector in Turkey. Public-Business Journal, 11(4), 183-218 (in Turkish).

Rivara, F. P., \& Thompson, D. C. (2000). Prevention of falls in the construction industry: evidence for program effectiveness. American Journal of Preventive Medicine, 18(4), 23-26. http://dx.doi.org/10.1016/S0749-3797(00)00137-9

Rubio, M. C., Martinez, G., Rubio, J. C., \& Ordoñez, J. (2008). Role of the civil engineer as a coordinator of safety and health matters within the construction sector. Journal of Professional Issues in Engineering Education and Practice, 134(2), 152-157. http://dx.doi.org/10.1061/(ASCE)1052-3928(2008)134:2(152)

Saari, J., \& Näsänen, M. (1989). The effect of positive feedback on industrial housekeeping and accidents; a long-term study at a shipyard. International Journal of Industrial Ergonomics, 4, 201-211. http://dx.doi.org/10.1016/0169-8141(89)90003-6

Salminen, S. (1995). Serious occupational accidents in the construction industry. Construction Management and Economics, 13(4), 299-306. http://dx.doi.org/10.1080/01446199500000035

Sorock, G. S., Smith, E. O., \& Goldoft, M. (1993). Fatal occupational injuries in the New Jersey construction industry 1983 to 1989. Journal of Occupational Medicine, 35(9), 916-921. http://dx.doi.org/10.1097/00043764-199309000-00015

Takala, J. (1999). Global estimates of fatal occupational accidents. Epidemiology, 10(1), 640-646. http://dx.doi.org/10.1097/00001648-199909000-00034

Tan, O. (2001). The costs of accidents in construction workplaces. Msc Thesis. Istanbul University, Institute of Health Science.

Tang, S. L., Lee, H. K., \& Wong, K. (1997). Safety Cost Optimization of Building Projects in Hong Kong, Construction Management and Economics, 15(2), 77-86. http://dx.doi.org/10.1080/01446199700000005

Tang, S. L., Ying, K. C., Chan, W. Y., \& Chan, Y. L. (2004). Impact of social safety investments social costs of construction accidents. Journal of Construction Engineering and Management, 22(9), 937-946. http://dx.doi.org/10.1080/0144619042000226315

Tudor, C., Van der Walt, M., Margot, B., Dorman, S. E., Pan, W. K., Yenokyan, G., \& Farley, J. E. (2014). Tuberculosis among health care workers in KwaZulu-Natal, South Africa: a retrospective cohort analysis. BMC Public Health, 14, 891-896. http://dx.doi.org/10.1186/1471-2458-14-891

Turkey Statistical Institute. (2013). Occupational accidents and work related health issues research report.

Wild, S., Pierpoint, T., McKeigue, P., \& Jacobs, H. (2000). Cardiovascular disease in women with polycystic ovary syndrome at long-term follow-up: a retrospective cohort study. Clinical Endocrinology, 52, 595-600. http://dx.doi.org/10.1046/j.1365-2265.2000.01000.x

\section{Copyrights}

Copyright for this article is retained by the author(s), with first publication rights granted to the journal.

This is an open-access article distributed under the terms and conditions of the Creative Commons Attribution license (http://creativecommons.org/licenses/by/3.0/). 